\title{
Committee for Small Body Nomenclature
}

CHAIRS: Pam M. Kilmartin (2002-2003), Jana Tichá (2003-2005) MEMBERS: M. F. A'Hearn (U.S.A.), K. Aksnes (Norway), J. Fernández (Uruguay), P. M. Kilmartin (New Zealand), Y. Kozai (Japan), D. Lazzaro (Brazil; since 2003), B. G. Marsden (U.S.A.), L. D. Schmadel (Germany), V. A. Shor (Russia), J. Tichá (Czech Republic), R. M. West (Denmark), G. V. Williams (U.S.A.), I. P. Williams (U.K.; since 2003), D. K. Yeomans (U.S.A.), and J. Zhu (China). D. W. E. Green (U.S.A.) serves just as a member for matters concerning comets.

\section{Comets}

As for comets 619 comets received names from July 2002 to June 2005. Of this naming 76 percent are SOHO comets and 11 percent include the name of the LINEAR project. A revision of the guidelines for naming comets has been completed in March 2003. The assistance of the director of CBAT, Daniel W. E. Green, in redrafting these guidelines was much appreciated by the committee.

\section{Minor Planets}

As for minor planets 2766 names of minor planets have been approved and published in the Minor Planet Circulars in the period July 2002--July 2005. In November 2002 the double milestone was reached: the 50 000th numbered minor planet and the 10 000th named minor planet. The total number of named minor planets was 12345 till June 2005. In comparison to previous triennium (more than 2800 names) the naming rate remained almost the same.

The leading role of the Lincoln Laboratory Near-Earth Asteroid Research (LINEAR) program in minor planet discoveries is evident in the fact that LINEAR names account for 35 percent of all the namings in the 2002-2005 triennium. The majority of the LINEAR names honor science students who are finalists in a series of science competitions and their teachers.

There are now nearly 100000 numbered minor planets, up from less than 44000 three years ago.

The CSBN has investigated methods of limiting the naming process. In the resolution adopted at the IAU General Assembly in July 2003 and printed on the MPC 49221 the CSBN recognized the need to limit the number of minor planets named and requests individual discoverers and teams to propose no more than two names each two months (corresponding to the timescale generally adopted for the publication of new names in the MPC). The CSBN members think that it is far better to concentrate on having smaller number of meaningful names having broad international appeal than to name all the tens of thousands of newly numbered main-belters. Not all but the majority of discoverers cooperate and this system seems to work.

Nevertheless, the CSBN does preserve the right to accept additional names that are considered particularly meritorious, especially for traditional cases such as the ACM series of names of planetary astronomers or the LINEAR science-fair student honors. 


\section{Most significant names}

3.1.

The namings of the minor planets (51823)-(51829) Rickhusband, Mikeanderson, Davidbrown, Kalpanachawla, Laurelclark, Ilanramon and Williemccool are dedicated to the final crew of the space shuttle Columbia. The 28th and final flight of Columbia (STS-107) was a 16-day mission dedicated to research in physical, life and space sciences. The seven astronauts aboard Columbia worked 24 hours a day, in two alternating shifts, successfully conducting approximately 80 separate experiments. On 2003 Feb. 1, the Columbia and its crew were lost over the southern United States during the spacecraft's re-entry into the earth's atmosphere. Names were given on the MPC 49283 in August 2003.

\section{2.}

Minor planet (90377) $2003 \mathrm{VB}_{12}$, an exceptionally interesting object in the outer solar system, was named Sedna. This naming has created some controversy, particularly in the community of amateur astronomers, but the Sedna problem was simply a procedural one. On the other hand the mythological name of Sedna is quite in line with the names of other unusual objects in the outer solar system and is to be commended for representing cultural and geographical diversity. This name was given on the MPC 52771 in September 2004 .

3.3.

The names for satellites of minor planet (87) Sylvia were approved by the CSBN in summer 2005 as the naming of the first triple asteroid system. Names (87) Sylvia I = Romulus and (87) Sylvia II = Remus were given on the IAUC 8582 in August 2005.

\section{Development of Guidelines}

4.1.

The following resolutions concerning minor planet names were adopted by the CSBN at the IAU General Assembly in Sydney on July 16 and 18, 2003: (1) The CSBN recognizes the need to limit the number of minor planets named and requests individual discoverers and teams to propose no more than two names each two months (i.e., to correspond to the timescale generally adopted for the publication of new names in the MPCs). (2) Names honoring persons, companies or products for no more than success in business are discouraged. Names or citations that resemble advertising will not be accepted.

\section{2 .}

A further resolution of some relevance to MPC readers adopted in Sydney reads: With the agreement of the WGPSN, the CSBN will assume responsibility for the naming of satellites of minor planets. Expanding on past practice, satellites of minor planets shall, where possible and appropriate, receive names closely related to the names of the primaries and suggestive of the relative sizes. For example, binary TNOs of comparable size should receive names of twins or siblings consistent with the current principle of using names of creation or underworld gods.

\section{3 .}

A simple change was made in the CSBN guidelines in order to handle cases similar to Sedna that might arise in the future. Accordingly, the CSBN has agreed that under some highly unusual circumstances it will in the future consider name proposals for 
minor planets before they are numbered. It is to be understood that this will occur only for objects of extraordinary interest. One important requirement is that the orbit is sufficiently well established that the object concerned will not be lost (unless, perhaps, it is about to collide with another solar-system member). In a qualifying case, a name should be submitted to the CSBN at least one week before it needs to be disseminated (e.g., at a press conference), assuming that it is in fact approved, and neither CSBN members nor the discoverers should announce the name until that particular dissemination.

\section{Miscellanous}

The fifth edition of the Dictionary of Minor Planet Names has been published by Springer-Verlag (Berlin-Heidelberg-New York) in 2003. It was edited, as in the past, by L. D. Schmadel (Astronomisches Rechen-Institut, Heidelberg), and prepared on behalf of IAU Commission 20. According to a resolution of IAU Division III at the General Assembly in Manchester in 2000 this publication attained the status of an official IAU reference work. It contains discovery and naming information for all 10038 minor planets that were named through Nov. 2002. 